\title{
Letters in the Earth Sciences: their historic value and present-day scientific relevance
}

\author{
Graziano Ferrari \\ SGA Storia Geofisica Ambiente, Bologna, Italy
}

\section{Introduction}

Scientific letters, of great importance in the history of science and scientific instrumentation, have a particular importance for those sectors of earth sciences in which structured observation networks are distributed across the territory, such as seismology, meteorology, geomagnetism and astronomy. It may come as a surprise to know that in the historical scientific letter collections there can be information having a certain scientific novelty. The current scientific relevance for seismology of the content of some historical letters is one of the aspects that most of all motivate an investment into this kind of research, more by the seismologists than by the historians of science. The experiences conducted up until now within the TROMOS project (INGV-SGA) framework have led us to identify the following types of information: description on the effects of seismic events; scientific comments to theories, to publications, etc.; graphs; reproductions of seismograms; news of loans of recordings; information and drawings of instruments, their location and orientation within the observatories.

The first three information types do not require particular comments, while the others are very important for seismological research and it is worth deepening several aspects.

Mailing address: Dr. Graziano Ferrari, SGA Storia Geofisica Ambiente, Via Bellombra 24/2, 40136 Bologna, Italy; e-mail: ferrari@sga-storiageo.it
Among the hundreds of the world's seismological observatories that have recorded earthquakes ever since the early 1890s (Ferrari, 2000), unfortunately not all of them have kept their recordings archives intact. In many cases these were partly or totally destroyed for a great variety of causes: human (state of abandonment, deliberate destruction or wars) and natural (fires, earthquakes, floods, etc.). At times the recordings of the most important earthquakes have been lost, with serious damage done to research. The reproductions of their seismograms and/or related information that can be gleaned from several letters, appropriately re-evaluated according to the current methods of analysis, can still provide important elements and return part of the information lost.

Within the framework of a broad international collaboration in the projects IASPEI SubCommittee Historical Instruments and Documents in Seismology and the ESC Working Group History of Seismometry (Ferrari, 2000), realised on the experience of the TROMOS project, the idea of starting up a specific research strand and collaboration into the scientific correspondence in the earth sciences was born. It is true that the experience hitherto performed mainly refers to the seismological field and at most to the meteorological field, but is should nevertheless be observed that the disciplinary distinction is rather recent and that in any case in Italy the meteorological and seismic observation has often been conducted in long-established astronomical observatories. Thus the materials, 
the observations and history of distinct disciplines mingle together. The astronomical observatories of Brera at Milan, Turin, Piacenza, the Collegio Romano in Rome, Capodimonte in Naples and Palermo, to mention just a few, are some examples of how a historical Italian astronomical observatories have constituted the natural home that hosted meteorological observation first, followed by seismological observation (Ferrari, 2002).

Numerous and largely identified files of historical correspondence of interest for meteorology and astronomy lie idle, uncatalogued, and even risking dispersion. The problem of cataloguing the files and above all managing them it with as view to consultation for study purposes has often been a disincentive that has prevented the preservation bodies from ever getting off the ground.

Within the scope of the TROMOS project, we are digitally scanning the files of scientific correspondence of some of the most important Italian seismological observatories. The catalogues and scans are conducted in collaboration with the conservatories of documentation, both public and private, and is made for their benefit.

The letters of the files of Timoteo Bertelli (1826-1905), Pietro Tacchini (1838-1905) and part of that of Giulio Grablovitz (1846-1928) have already been submitted to electronic scanning, respectively held at the Centro Studi Storici Barnabiti of Rome (transferred there from its original site of production and preservation, the «alla Querce» Boarding School of Florence), the Ufficio Centrale di Ecologia Agraria in Rome and at the home of the descendants of Grablovitz (temporarily kept at SGA). It is no coincidence that the first systematic digital scan was performed on the Tacchini file: he was an astronomer, 'meteorologist' and 'seismologist', at least from the institutional point of view.

The digital archive hitherto produced has brought together over 7000 letters, for a total of over 11000 pictures, received by Tacchini, Bertelli and Grablovitz from over 800 correspondents, all surveyed in the TROMOS database and documented by all the biographical information available.

Modern computer technologies allow us to store and distribute, via DVD-ROM and the Internet, the most diverse information forms and thus make it possible to realise what only a few years ago was unthinkable: a single letters archive concerning the scholars of earth sciences.

The project, enlarged to embrace a broader community of scholars, aims to promote and foster the identification, cataloguing, and electronic scanning of the letters, thus making available the files to of interest for the study of the history of earth sciences and astronomy.

Parallel to the project we also aim to enhance the recovery in electronic format of everything hitherto published: catalogues of letters, registers, integral letter transcriptions; this phase should also be flanked by a digital scanning of the letters themselves.

Cataloguing, scans and online availability are performed respecting the rights established by the law and by the specific agreements stipulated with the public or private bodies that preserve the files subjected to the study.

In order to discuss the methodological aspects of the study of the scientific correspondence and their scientific relevance, a seminar has been organised for 10th May 2002, promoted by the author in collaboration with the Istituto Nazionale di Geofisica e Vulcanologia (INGV) and the Ufficio Centrale di Ecologia Agraria (UCEA), at the congress hall of the UCEA, historic headquarters of meteorology and seismology in Italy. At the seminar, apart from the scholars most committed to studies of this kind over the past few years, the descendants of the most illustrious Italian scholars of the earth sciences have also been invited: Mario Baratta (1868-1935), Pietro Caloi (1907-1978), Michele Stefano de Rossi (18341898), Giulio Grablovitz (1846-1928) and Quintino Sella (1827-1884), besides a prestigious representation of the public, private and ecclesiastic Italian archives, of interest to this sector.

\section{The seminar}

The seminar was held under the splendid Renaissance ceilings of the UCEA, furbished to host congresses and exhibitions.

In order to represent the various situations existing in this particular study sector and the 
multidisciplinary and interdisciplinary characteristics of the various approaches, the day of study developed along five strands: 1) scientific letters: study traditions and prospects; 2) fragments of the European context; 3 ) case studies in Italy; 4) places of observation; 5) places of preservation.

Domenico Vento (Director of the UCEA, Rome) opened the session with a welcoming message that traced back the stages from the birth and the transformations of the Office he is directing. Vento briefly discussed the great historic and scientific value of the documentary and instrumental assets of the UCEA, generally acknowledged for some time. He also recalled the long and well-established tradition, within the TROMOS project, between the UCEA on the one hand and INGV and SGA on the other, and he expressed his hope that the renewed cultural understanding between these bodies could achieve new and important objectives.

\subsection{Scientific letters: study traditions and prospects}

This section was dedicated to the relating of research experiences having a consolidated tradition, and two talks on astronomy and seismology were given. There also emerged the international character that this kind of research can have, given the universal nature of the research itself and the relationship between the scholars.

Pasquale Tucci (Institute of General Applied Physics, University of Milan) with his talk on The correspondence between Otto Struve and Giovanni Virginio Schiaparelli (1864-1904), two eminent astronomers who lived between the 19th and 20th centuries, presented by means of the study of an important scientific collection, a clear-cut example of the potential that this kind of documentary evidence has for the history of science, embedding it in the cultural and political context of the day. In reconstructing, through some 280 letters preserved in Milan and Pulkovo (Russia), the major stages in the scientific and public lives of the two scholars, Tucci also paused to reflect on the specific value of the testimonies provided by this kind of documentation. For example, its crucial role in the reconstruction of the history of international scientific institutions such as the International Astronomical Union, established and developed thanks to those scholars whose collaboration went far beyond the official availability granted by the various States.

Graziano Ferrari (SGA Storia Geofisica Ambiente, Bologna) with his talk on Correspondence in Seismology, historical value and present-day scientific relevance outlines the role and the importance of the letters between scholars of seismology, developing and exemplifying some of the aspects alluded to in the introductory part of this text. He also mentioned the cataloguing project, the electronic reproduction and the dissemination of the scientific correspondence in the earth sciences, started up within the TROMOS project, inviting those in attendance to join in as well.

\subsection{Fragments of the European context}

A couple of experiences of recovery and analysis of correspondence performed in the European field help us to contextualise the Italian experience in this sector. In one case it is a matter of a very advanced experience, belonging to the British tradition, which documents the status and the study method of the New Dictionary of National Biography (DNB) and the materials available to the researchers. The second case deals with a research experience performed in Spain, similar to the one performed in Italy within the TROMOS project.

Anita McConnell (Research editor, New DNB Oxford University Press) with her talk on the 'New Dictionary of National Biography': A New Look at British Earth Scientists presented the contents of the DNB, with particular regard for the British earth scientists, and the places, the materials and the instruments of their research. The New Dictionary of National Biography: (http://www.oup.co.uk/newdnb) contains some 60000 names of British people active from ca. 60 B.C. to 2000 A.D., in Scotland, Ireland, North America and other colonies, and of foreign people who were active in Britain. It includes more than 100 people who were active in the earth sciences. In preparing their articles, 
searches were made for their correspondence and papers.

The survival and whereabouts depends largely on the date, affiliation, and family interests of the scientists concerned. McConnell also made an overview of the main institutions holding documents of interest for the DNB, such as university and the scientific societies archives, the Public Records Office in London and the John Milne Library.

Josep Batló (CRHT Dept. De Matematica Aplicada I, Barcelona) with his contribution on Scientists and scientific associations in Catalonia (Spain) in the early 20th century: manuscript versus published research brought his study experience within the seismological and meteorological field, relating to published and unpublished documentation on scholars, observatories and scientific associations in Catalonia. He also highlighted the present-day relevance of the various kinds of documentation, and in particular the letters, in regard to the research in the meteorological and seismological fields, with some examples for Catalonia of the reconstruction of the macroseismic maps of historical earthquakes and climatological maps.

\subsection{Case studies in Italy}

One of the main figures in the history of the earth sciences at the end of the 18th century is Pietro Tacchini, a leading personality in astronomy, who from 1879 had the scientific, political and organisational skills to set up and develop the national meteorological and geodynamic services within the scope of the Central Meteorology Office (and from 1887 also Geodynamics). Three talks outlined the complex biographical profile of this scientist seen from different disciplinary perspectives.

Letizia Buffoni and Edoardo Proverbio (Astronomical Observatory of Brera, Milan) with The contribution of Angelo Secchi and Pietro Tacchini to the birth of earth and solar meteorology: the role of correspondence, developed some aspects of the scientific and human relations existing between Pietro Tacchini and Angelo Secchi, two of the greatest 18th century Italian astronomers, through the study of the letters sent by Tacchini to Secchi preserved at the Archives of the Pontifical Gregorian University, Rome.

Ileana Chinnici (Astronomical Observatory, Palermo) in his talk on Pietro Tacchini 'astronomer' in the scientific correspondence preserved at the UCEA outlined Tacchini's scientific biography with special regard for the contribution of this great scientist in reorganising the network of astronomical observatories, documented by the letters of the Tacchini epistolary archive preserved in the Library of the UCEA.

Franca Mangianti (Central Office of Agrarian Ecology, Rome) Pietro Tacchini 'meteorologist' in the epistolary documentation of the UCEA (1879-1899) went over the experience of Tacchini as a meteorologist and the first director of the UCEA, documenting it with letters from the Tacchini epistolary archive of the UCEA (wholly digitally scanned by the TROMOS project) and that of the Archive of the Pontifical Gregorian University.

Francesco Obrizzo (INGV-OV, Naples) and Edvige Schettino (Department of Physics, University of Naples) presented a contribution on The machines of the Bourbons in Naples between Collection and Museum: verbal sources and others (1840-1850) in which they recalled how the Royal Cabinet, made up of an initial nucleus of 200 scientific instruments, where magnetic, meteorological and time measurements were also made, acted as a teaching laboratory for the heir to the throne Francis II of Bourbon. The instrumental resources recovered in the ten-year period 1985-1995 are the subject of study, supported by the documentary and epistolary evidence.

\subsection{Places of observation}

The changing strategies for monitoring the observation networks, both seismological and meteorological, many of which are often centralised and heavily automated, have radically modified the functions of several ancient observatories, the surviving ones, transforming them in some cases into places for the preservation of the historical materials of their history of observation. In other cases these 
scientific institutes have been able to adapt to the new requirements of modern research and represent the places where modern monitoring systems cohabit with the preservation and the valorisation of the material traces of the long historical tradition of observation. In the hope of providing a broad picture of the sites having a long scientific tradition in the seismological and meteorological field, the representatives of the various observatories that are still active were invited, amongst which the «Vincenzo Nigri» Observatory of Foggia, still kept working by the descendants of the founder, and the Ximenian Observatory of Florence of the Scolopi fathers. Owing to other commitments, only the Piacenza Observatory was able to accept the invitation.

Graziano Ferrari (SGA Storia Geofisica Ambiente, Bologna) and Matteo Cerini (Director of the Observatory «Alberoni», Piacenza) presented a contribution on The seismological correspondence of the 'Alberoni' observatory of Piacenza, first of all recalling that the observatory of Piacenza is one of the rare cases of a long scientific tradition, still active, that has its roots in the 1870 s, and where the modern instruments are side by side with the ancient ones and the related historical documentation. From the Observatory's letters archive, which Cerini is patiently recomposing, the more recent history of the Observatory and its instruments is emerging: from the events that brought them to Piacenza in the 1920s and their characteristics. All these elements are of great scientific value today of we consider the fact that the Observatory has intact over 15000 original seismograms of enormous scientific value.

\subsection{Places of preservation}

The Archive and the Library of the Barnabite study centre, the Central State Archive, the Library of the Neapolitan Society for Local History and the Archive of the Pontifical Gregorian University are very important examples of the contribution that can come from these 'historical containers' both because of the importance of the historical documentary resources contained therein, and the availability to collaborate demonstrated by the bodies which took part in the seminar and the expertise of their representatives.

Filippo Lovison (Barnabite Historical Studies Centre, Rome) in his The earth sciences in the epistolary archives of the Barnabite scientists briefly but incisively recalled the contribution of several 19th and 20th century Barnabite scientists to the progress in several sectors of the earth sciences such as: Timoteo Bertelli, Francesco Denza (1834-1898), Camillo Melzi d'Eril (18511929), to mention some of the most important. In recalling the long collaboration of the Barnabites with the research performed within the TROMOS project, Lovison stressed how important it is for the historical sites preserving the ancient epistolaries not to be considered merely as 'document containers', but as centres for the study and the valorisation of the historical documentation they are preserving. It is important for the archive to benefit, as in the case of the TROMOS project, of scientific collaborations that can help to draw from the documentation the historical and currently relevant scientific contents. In confirming the Centre's availability and its willingness to collaborate with the scholars and with the project on the scientific correspondence as described by Ferrari, Lovison underlined the need to reflect on some aspects of the dissemination of the digital copies of the letters, especially via the Internet.

Nella Eramo (Central State Archive, Rome) with her talk on The archive of the General Directorate of Agriculture in the Central State Archive, outlined a brief historical and archival profile of the archive of the General Directorate of Agriculture, with special regard to the repercussions on the history of the earth sciences. These materials often document the reasons, the conditioning, the motivations behind the choices made and the paths taken by scientists and public administrators in the development of the meteorological and seismological observational networks. Eramo also recalled the important documents in the history of geology, citing some documents dating back to the early 1870 s in which the urgent need for a geological map of the Kingdom of Italy was manifest.

Paola Milone (Neapolitan Society for the Local History, Naples - SNSPN) with her presentation on The Seismic Archive of the Nea- 
politan Society for the Local History, Milone first of all recalled the present-day knowledge on the origins of this important Archive, established upon the nucleus of the library and archive belonging to the French naturalist Alexis Perrey, acquired by the Club Alpine of Naples (CAI), and the reasons that brought this wealth of information to Naples in 1878, later given by the CAI to the SNSPN in 1893 or 1894 . The Society is currently cataloguing all the library, documentary and iconographic material available in the archive, in which there stands out the substantial epistolary collection of Perrey himself, that goes from 1842 to 1877 with some gaps, having nonetheless an indisputable historical and scientific value for seismology.

Lydia Salviucci Insolera (Director of the Archive of the Pontifical Gregorian University, Rome) with her talk on The scientific archives of the Pontifical Gregorian University: research methods, coordination and future potential outlined the principal contents of the Archive with particular regard to the most important Jesuit scholars, particularly in physics and astronomy. She confirmed the opening and the great attention and interest of the Gregorian University for collaboration with the scientific world and the historians of science. She put forward some proposals, amongst which that of setting up a communications network among the scholars who may be a point of reference for the Archive's operators, and selecting together the Archive's materials relating to Jesuit scholars of special interest for the earth sciences.

The scholars who took part in the seminar left one another hoping for further collaboration within the scope of the project, subsequently named Letters in Earth Sciences, for the recovery, reproduction and valorisation of the scientific correspondence in the earth sciences.

The seminar has also been followed up on a European scale during the 28th ESC General Assembly in Genoa, where the Letters in Earth Sciences project was presented, arousing positive feedback from a number of seismologists operating in the historical sites of European seismology preserving an important epistolary documentation.

Contacts are being fostered to formalise the collaboration between the INGV and bodies and scholars interested in participating in the project. A web site is under construction, for the moment a demo version is available (at the address http:// 80.117.141.2/letters), which will allow us to disseminate the historical epistolary materials, the reproductions, the elaborations and more generally the products of the collaborations developed. The project is open to all the researchers and the institutions that may be interested, and they are invited to get in touch with the author.

\section{REFERENCES}

FERRARI, G. (2000): The new IASPEI Sub-Committee Historical instruments and related documents in seismology: goals, objectives and first results, in Proceedings of the XXII IUGG General Assembly, Birmingham, 19-30 July 1999, Sismol. Res. Lett., 71 (5), 553-561

FERRARI, G. (2002): Census, filing and elaboration of scientific letters in the earth sciences, Nuncius, 17 (1), 307-320. 